\title{
Experience with intrawound vancomycin powder for posterior cervical fusion surgery
}

\author{
Joel R. Martin, MD, ${ }^{1}$ Owoicho Adogwa, MD, MPH, ${ }^{1}$ Christopher R. Brown, MD, ${ }^{2}$ \\ Maragatha Kuchibhatla, PhD, ${ }^{3}$ Carlos A. Bagley, MD, ${ }^{1}$ Shivanand P. Lad, MD, PhD, ${ }^{1}$ \\ and Oren N. Gottfried, MD'
}

\begin{abstract}
1Division of Neurosurgery, Department of Surgery; ${ }^{2}$ Division of Orthopaedic Surgery; and ${ }^{3}$ Department of Biostatistics and Bioinformatics, Duke University Medical Center, Durham, North Carolina
\end{abstract}

\begin{abstract}
OBJECT Recent studies have reported that the local delivery of vancomycin powder is associated with a decrease in spinal surgical site infection. This retrospective cohort study compares posterior cervical fusion cases before and after the routine application of spinal vancomycin powder to evaluate the ability of local vancomycin powder to prevent deep wound infection after posterior cervical spinal fusion.
\end{abstract}

METHODS Posterior cervical fusion spinal surgeries performed at a single institution were reviewed from January 2011 to July 2013. Each cohort's baseline characteristics, operative data, and rates of wound infection were compared. Associations between infection and vancomycin powder, with and without propensity score adjustment for risk factors, were determined using logistic regression.

RESULTS A total of 289 patients (174 untreated and 115 treated with vancomycin powder) were included in the study. The cohorts were similar in terms of baseline and operative variables. No significant change in deep wound infection rate was seen between the control group (6.9\%) and intervention group (5.2\%, $p=0.563)$. Logistic regression, with and without propensity score adjustment, demonstrated that the use of vancomycin powder did not impact the development of surgical site infection (OR 0.743 [95\% Cl 0.270-2.04], $p=0.564$ ) and (OR 0.583 [95\% Cl 0.198-1.718], $p=0.328$ ), respectively.

CONCLUSIONS Within the context of an ongoing debate on the effectiveness of locally administered vancomycin powder, the authors found no significant difference in the incidence of deep wound infection rates after posterior cervical fusion surgery with routine use of locally applied vancomycin powder. Future prospective randomized series are needed to corroborate these results.

http://thejns.org/doi/abs/10.3171/2014.9.SPINE13826

KEY WORDS local anti-infective agents; spinal fusion; spinal stenosis; treatment outcome; vancomycin; wound infection; cervical fusion

$\mathrm{T}$ He incidence of postoperative surgical site infections (SSIs) after cervical spine surgery is reported to range from $0.8 \%$ to $15.0 \% .^{2,17-20,27}$ Compared with lumbar surgeries, Gruskay et al. showed that cervical fusion cases were associated with a significantly lower rate of infection ( $\mathrm{n}=5023,4.3 \%$ vs $2.75 \%, \mathrm{p}=0.003)$, with posterior cervical fusion cases having a significantly higher rate of infection than anterior cervical cases $(\mathrm{n}=$ $2544,6.0 \%$ vs $0.4 \%, \mathrm{p}<0.001) .{ }^{5}$ Postoperative infections have a deleterious impact on patients, as they often require more hospitalizations, surgical procedures, and resultant increased economic burden. ${ }^{25}$ Furthermore, patients who develop SSIs have an elevated mortality risk..$^{1,6,7}$ Given the incidence of deep wound infections, several authors explored and subsequently published their results on locally applied prophylactic vancomycin antibiotic powder, in addition to systemic antibiotics, to reduce postoperative spinal SSIs. ${ }^{2-4,9,13-17,20-22,24}$

Perioperative vancomycin powder is an attractive option for additional prophylaxis against postoperative SSI due to its low cost and broad coverage. Numerous studies have shown that the addition of local vancomycin

ABBREVIATIONS BMI = body mass index; $\mathrm{CDC}=$ Centers for Disease Control and Prevention; $\mathrm{COPD}=$ chronic obstructive pulmonary disease; $\mathrm{CTJ}=$ cervicothoracic junction; EBL = estimated blood loss; MRSA = methicillin-resistant Staphylococcus aureus; SSI = surgical site infection.

SUBMITTED September 4, 2013. ACCEPTED September 29, 2014

INCLUDE WHEN CITING Published online November 7, 2014; DOI: 10.3171/2014.9.SPINE13826.

DISCLOSURE The authors report no conflict of interest concerning the materials or methods used in this study or the findings specified in this paper. 
powder to standard systemic antibiotic prophylaxis reduced postoperative spinal SSI rates from $2.6 \%-15 \%$ to $0 \%-2.5 \% .2,4,14,15,17,20-22 \mathrm{~A}$ few cohort studies have looked at posterior cervical fusion cases and have reported significant reductions in the incidence of postoperative deep SSI rates from $10.9 \%-15.0 \%$ to $0 \%-2.5 \%$ after the introduction of perioperative vancomycin powder. ${ }^{2,17,20}$ However, these studies were limited by small cohort patient sizes, with fewer than 172 total patients, and high control (nonvancomycin) postoperative SSI rates. Furthermore, a recent study published by Mariappan et al. ${ }^{11}$ highlighted the adverse systemic effects of locally applied vancomycin powder and questioned its effectiveness in reducing the incidence of postoperative spinal SSIs. With a relatively larger cohort of patients $(n=289)$, this study will provide an improved analysis of the efficacy of perioperative vancomycin powder in posterior cervical fusion cases.

The aim of this study is to compare the incidence of postoperative deep SSI rates in patients undergoing posterior cervical fusion surgery before and after the routine application of locally applied vancomycin powder at our institution.

\section{Methods \\ Patient Selection}

This study compares postoperative deep SSI rates in patients undergoing posterior cervical fusion surgery before and after the routine application of locally applied vancomycin powder by one of 8 spine surgeons at our institution. The institutional review board approved this study, which consisted of a retrospective review of hospital records from January 2011 to July 2013 of adult spinal surgery patients. The inclusion criteria consisted of patients older than 18 years who had undergone posterior cervical (occipitocervical, cervical only, and cervicothoracic) spinal fusion using screw-rod instrumentation. Inclusion etiologies included degenerative, deformity, neoplastic, and traumatic pathologies. Exclusion criteria included infectious etiologies and nonfusion or laminoplasty cases. Patient demographics, clinical presentation, comorbidities, radiological studies, and all treatment variables were reviewed for each case.

\section{Standard Pre- and Postoperative Systemic Prophylactic Antibiotic Regimen}

All patients received standard systemic antibiotic prophylaxis consisting of intravenous cefazolin within 1 hour of surgical incision followed by intravenous cefazolin every 8 hours for 1 day. If the patient was allergic to penicillin, clindamycin was used instead. Other intravenous antibiotics that were used infrequently included piperacillin/ tazobactam and vancomycin. All patients were prepared with chlorhexidine. Fusion levels were determined by preoperative imaging. Before skin closure, irrigation with normal saline was performed.

\section{Treatment and Control Cohorts}

Two patient cohorts were developed. The treatment group consisted of consecutive patients who received $2 \mathrm{~g}$ of intraoperative vancomycin powder (April 2012-July 2013), spread throughout the local wound. The powder was placed directly on the deep wound and subfascial muscle tissues, taking care not to expose bone graft or dura. The control group consisted of consecutive patients who underwent surgery prior to the institutional use of vancomycin powder (January 2011-March 2012). Patients who lacked documentation of affirmative or negative vancomycin usage were excluded from analysis. The surgical approach involved an open midline posterior incision for all patients. Titanium instruments, autograft and dimineralized bone matrices, and cortical cancellous chips were used in all cases.

The decision to use subfascial drains was based on surgeon preference. However, in most cases subfascial drains were used. In all cases, the wounds were closed with nonabsorbable suture in the muscle, fascia, and subcutaneous layers, and with staple or suture closure of the skin. After skin closure, incisions were cleaned again with chlorhexidine, and a sterile dressing was applied. Dressings and drains were kept in place until the 2nd postoperative day.

\section{Diagnostic Evaluation}

The definition of a deep SSI established by the Centers for Disease Control and Prevention (CDC) was used to make an SSI diagnosis. ${ }^{10}$ According to the CDC definition, deep space incisional SSIs all occur within 30 days after surgery. Additionally, they involve purulent drainage, isolation of organism, signs or symptoms of infection (such as pain or tenderness, localized swelling, redness, or heat) combined with positive culture results, and diagnosis by a surgeon or attending physician. Thus, for this study, an SSI was defined as being diagnosed during the initial hospitalization or during a hospital readmission or postoperative clinic appointment within 30 days of the surgery.

All patients in this study had standard laboratory tests on admission to the hospital including erythrocyte sedimentation rate, peripheral white blood cell count, C-reactive protein, complete urine analysis, and microbiology and blood cultures. Erythrocyte sedimentation rate was determined by the Westergren method and was considered abnormal if greater than $15 \mathrm{~mm} / \mathrm{hr}$. C-reactive protein was considered abnormal if greater than $5 \mathrm{mg} /$ dl. Bacterial identification and susceptibility testing were performed according to the guidelines of the CDC.

\section{Clinical Parameters}

Preoperative and intraoperative data for each patient were collected using patient charts and computerized medical records. Surgical infection risk factors were documented for each patient, including body mass index (BMI), obesity, diabetes mellitus, insulin use, chronic steroid use, prior cervical surgery, chronic obstructive pulmonary disease (COPD), tobacco use, and osteoporosis. Pertinent operative details were also collected, including number of levels instrumented, involvement of the cervicothoracic junction (CTJ), estimated blood loss (EBL), duration of anesthesia, intraoperative steroid use, blood transfusion, use of cell saver blood, and dural tear.

\section{Statistical Analysis}

Bivariate associations of vancomycin powder with base- 
line characteristics, operative data, and rates of wound infection were determined using chi-square tests for categorical variables and Wilcoxon tests for continuous variables. Variables used in the propensity score model to predict use of vancomycin powder included age, BMI, duration of anesthesia, EBL, long-term use of steroid, intraoperative steroid use, number of levels instrumented, tobacco use, diabetes, coronary artery disease, COPD, obesity, osteoporosis, prior cervical fusion, CTJ involvement, neoplastic etiology, and traumatic etiology. Associations between postoperative infection and vancomycin powder, with and without propensity score adjustment for risk factors, were determined using logistic regression. Significance of the results was assessed at alpha $=0.05$. Analysis was conducted using SAS (version 9.3, SAS Inc.).

\section{Results}

A total of 289 adult patients undergoing posterior cervical fusions were included in the study, with 174 patients (91 males and 83 females) in the untreated group and 115 patients (58 males and 57 females) in the vancomycintreated group. Two patients were excluded due to incomplete records. As shown in Table 1, the untreated and treated groups were statistically similar $(p>0.05)$ with regard to baseline and operative variables, with the exception of mean patient age (untreated 57.6 years, treated 62.3 years; $p=0.009$ ), cases that crossed the CTJ (untreated $41.4 \%$, treated $57.4 \%$; $\mathrm{p}=0.008$ ), and mean number of levels instrumented (untreated 4.4, treated 4.8; $\mathrm{p}=$ 0.033 ), which were slightly higher in the treated group. Mean BMI (untreated 28.0, treated 29.3; $\mathrm{p}=0.293$ ) and prevalence of diabetes (untreated $18.4 \%$, treated $21.1 \%$; $\mathrm{p}=0.577$ ) were similar between the cohorts. Tobacco use was higher in the untreated cohort (untreated 20.7\%, treated $12.2 \% ; \mathrm{p}=0.061$ ).

The mean duration of anesthesia and EBL were similar between the cohorts: (untreated 279.5 minutes, treated 277.6 minutes; $p=0.747$ ) and (untreated $447.8 \mathrm{ml}$, treated $436.4 \mathrm{ml}, \mathrm{p}=0.585$ ), respectively. Postoperative drains were used in a similar number of patients (untreated $90.2 \%$, treated $89.6 \% ; p=0.854$ ). Lastly, both the untreated and treated groups did not have a significant difference in deep SSI rates (untreated 6.9\%, treated 5.2\%; $\mathrm{p}=0.563$ [Table 1]).

A comparison of other baseline and operative variables between untreated and treated patients with a deep SSI is shown in Table 2. The mean number of postoperative days to infection was significantly longer in the treated cohort (untreated 13.9 days, treated 22.3 days; $p=$ $0.024)$. Similarly, there were more smokers in the treated cohort (untreated $0 \%$, treated 33.3\%; $\mathrm{p}=0.034$ ).

There was no significant difference between choice of pre- and perioperative intravenous antibiotics: cefazolin (untreated 85.6\%, treated 87.8\%; $\mathrm{p}=0.593$ ), clindamycin (untreated $10.3 \%$, treated $9.6 \% ; \mathrm{p}=0.829$ ), vancomycin (untreated $3.4 \%$, treated $2.6 \% ; \mathrm{p}=0.688$ ), and a single case of piperacillin/tazobactam.

A detailed description of each SSI is shown in Tables 3 and 4 for vancomycin-treated and untreated patients, respectively. There was no significant difference in culture results for SSIs. The majority of documented infections in both groups were due to either 1) gram-positive cocci (other than methicillin-resistant Staphylococcus aureus [MRSA]) in 10 of 12 untreated patients and 5 of 6 treated patients, or 2) gram-negative rods in 4 of 12 untreated patients and 2 of 6 treated patients. There were no MRSA infections in either group, and 6 cultures grew multiple organisms (4 of 12 untreated patients and 2 of 6 treated patients).

Unadjusted odds of use of vancomycin powder did not significantly decrease SSI (OR 0.743 [95\% CI 0.270-2.04], $p=0.564)$. Logistic regression, adjusted with quintiles of the propensity score for the risk factors of vancomycin powder on SSI, was also not predictive of postoperative infection (OR 0.583 [95\% CI 0.198-1.718], $\mathrm{p}=0.328$ ).

\section{Discussion}

Local powdered intrawound vancomycin is an attractive option for additional prophylaxis against postoperative spinal SSIs. Powdered vancomycin is inexpensive, appears to carry a lower risk of systemic complications compared with the intravenous form, and has broad coverage against typical organisms responsible for deep wound infections. Most initial studies have supported adjunctive powdered vancomycin, reporting decreased rates of postoperative wound infection and no adverse side effects. . $3,14,15,17,20-22,24^{2}$

Local vancomycin has long been tested in sternotomy wounds following cardiac surgery. In a 1989 blinded, randomized study involving 416 patients, Vander Salm et al. reported a significant reduction of sternal infections ( $3.6 \%$ vs $0.45 \%, p=0.02)$ with topical vancomycin applied to the cut edges of the sternum. ${ }^{24}$ Recently, Lazar et al. used adjunctive topical vancomycin powder in 36 cardiac surgery cases and reported no occurrences of postoperative sternal infections or renal toxicity during the 12-month follow-up period. The group also measured serum vancomycin levels after each postoperative day, which showed a significant decrease in serum vancomycin levels from the day of surgery to the 6th postoperative day $(\mathrm{p}<0.001) .{ }^{9}$ Ozcan et al. used rodent models to study MRSA sternotomy infections. The group used topical and intravenous vancomycin on rats with deep sternal wounds inoculated with MRSA and reported a significant $(p<0.05)$ reduction in MRSA wound organisms in 3 treated groups (topical, intravenous, and topical plus intravenous), with topical plus intravenous having the largest reduction. ${ }^{16}$

Several studies have looked at the addition of local vancomycin powder to standard systemic antibiotic prophylaxis in posterior spinal fusion surgery (Table 5). Cohort studies showed that vancomycin powder significantly reduced postoperative SSIs in adult thoracolumbar fusion surgery $(\mathrm{n}=165-1732,2.6 \%-12 \%$ vs $0 \%-0.2 \%, \mathrm{p}<0.001),{ }^{21,22}$ posterior fusion after traumatic etiologies $(\mathrm{n}=110,13 \%$ vs $0 \%, \mathrm{p}=0.02),{ }_{1}^{15}$ and posterior cervical decompression and fusion surgeries $(\mathrm{n}=171-576,1.73 \%-15 \%$ vs $0 \%-2.5 \%$, $\mathrm{p}<0.05)^{2,17,20}$ Similarly, after introduction of vancomycin powder, Molinari et al. reported a low (1.20\%) SSI rate in spine fusion surgery $(\mathrm{n}=663),{ }^{14}$ and Gans et al. reported a low (3.4\%) SSI rate in pediatric spine deformity fusion cas- 
TABLE 1. Comparison of patients undergoing posterior cervical fusion spine surgery before and after the introduction of vancomycin powder*

\begin{tabular}{|c|c|c|c|}
\hline Characteristic & Untreated $(n=174)$ & Treated $(n=115)$ & $p$ Value \\
\hline \multicolumn{4}{|l|}{ Baseline features } \\
\hline Mean age in yrs & $57.6 \pm 14.2$ & $62.3 \pm 12.1$ & $0.009 \dagger$ \\
\hline Diabetes & $32(18.4)$ & $24(21.1)$ & 0.577 \\
\hline Insulin & $10(5.7)$ & $9(7.8)$ & 0.485 \\
\hline Mean BMI & $28.0 \pm 5.8$ & $29.3 \pm 7.1$ & 0.293 \\
\hline Obesity & $62(35.6)$ & $43(37.4)$ & 0.761 \\
\hline Prior cervical fusion & $39(22.4)$ & $29(25.2)$ & 0.582 \\
\hline Current alcohol abuse & $8(4.6)$ & $3(2.6)$ & 0.387 \\
\hline Current smoker & $36(20.7)$ & $14(12.2)$ & 0.061 \\
\hline Illicit drug user & $7(4.0)$ & $1(0.9)$ & 0.110 \\
\hline CAD & $23(13.2)$ & $14(12.2)$ & 0.795 \\
\hline Osteoporosis & $14(8.0)$ & $6(5.2)$ & 0.354 \\
\hline COPD & $17(9.8)$ & $19(16.5)$ & 0.089 \\
\hline Current steroid use & $9(5.2)$ & $12(10.4)$ & 0.092 \\
\hline Hyperlipidemia & $68(39.1)$ & $53(46.1)$ & 0.237 \\
\hline Hypertension & $111(63.8)$ & $76(66.1)$ & 0.690 \\
\hline \multicolumn{4}{|l|}{ Location/etiologies } \\
\hline Deformity & $47(27.0)$ & $38(33.0)$ & 0.271 \\
\hline Degenerative & $95(54.6)$ & $53(46.1)$ & 0.157 \\
\hline Neoplasm & $10(5.7)$ & $8(7.0)$ & 0.677 \\
\hline Trauma & $22(12.6)$ & $16(13.9)$ & 0.755 \\
\hline Cross CTJ & $72(41.4)$ & $66(57.4)$ & $0.008 \dagger$ \\
\hline \multicolumn{4}{|l|}{ Operative details } \\
\hline Mean no. of levels instrumented & $4.4 \pm 2.0$ & $4.8 \pm 2.0$ & $0.033 \dagger$ \\
\hline Mean EBL in $\mathrm{ml}$ & $447.8 \pm 701.4$ & $436.4 \pm 497.9$ & 0.585 \\
\hline Mean duration of anesthesia in mins & $279.5 \pm 98.2$ & $277.6 \pm 106.6$ & 0.747 \\
\hline Use of postop drain & $157(90.2)$ & $103(89.6)$ & 0.854 \\
\hline Intraop steroid use & $70(40.2)$ & $49(42.6)$ & 0.688 \\
\hline Blood transfusion & $21(12.1)$ & $17(14.8)$ & 0.504 \\
\hline Use of cell saver & $3(1.7)$ & $1(0.87)$ & 0.543 \\
\hline Dural tear & 0 & 0 & \\
\hline \multicolumn{4}{|l|}{ Outcomes } \\
\hline Deep SSI & $12(6.9)$ & $6(5.2)$ & 0.563 \\
\hline
\end{tabular}

$\mathrm{CAD}=$ coronary artery disease.

* Values are number of patients (\%) unless indicated otherwise. Mean values are presented as the mean \pm SD.

$\dagger$ Statistically significant.

es $(n=87) .^{3}$ In a cost analysis, Godil et al. postulated that decreased SSI rates due to vancomycin powder can lead to a potential cost savings of $\$ 438,165$ per 100 patients. ${ }^{4}$ In all of these studies, no adverse events or postoperative complications associated with the use of vancomycin powder were noted in any of the intervention groups.

Conversely, 2 groups reported no significant change in postoperative deep wound infection. Mohammed et al. compared open vascular procedures with and without intrawound vancomycin powder..$^{13}$ In the 454-patient study, there was a small but statistically significant decrease in the 30-day incidence of superficial infections (18.9\% vs $11.5 \%, p=0.033$ ), but no significant difference in the incidence of deep wound infections $(6.1 \%$ vs $5.7 \%, \mathrm{p}=$
$0.692)$ or overall dehiscence rates $(22.2 \%$ vs $17.7 \%, p=$ $0.239)$. The group postulated that the blunted effect of local vancomycin on deep wounds could be due to the local vascular environment resulting in poor systemic absorption of the local antibiotic lessening its systemic effect on deep wound infections. Similarly, Tubaki et al. reported no change in postoperative SSI rates in spinal fusion cases $(1.99 \%$ vs $1.98 \%) .{ }^{23}$ The safety of vancomycin powder has also been challenged in a recent case report by Mariappan et al., who described an anaphylactic reaction resulting in circulatory collapse in a 52-year-old woman with metastatic breast cancer, after topical application of vancomycin powder during thoracic spine surgery. ${ }^{11}$

Similarly, our study did not show a significant reduction 
TABLE 2. Comparison of patients who underwent posterior cervical fusion spine surgery and had a postoperative SSI, before and after the introduction of vancomycin powder*

\begin{tabular}{|c|c|c|c|}
\hline Characteristic & Untreated $(n=12)$ & Treated $(n=6)$ & p Value \\
\hline \multicolumn{4}{|l|}{ Baseline features } \\
\hline Mean age in yrs & $62.1 \pm 9.3$ & $62.7 \pm 13.3$ & 0.851 \\
\hline Diabetes & $3(25.0)$ & $2(33.3)$ & 0.710 \\
\hline Insulin & $2(16.7)$ & $2(33.3)$ & 0.423 \\
\hline Mean BMI & $29.1 \pm 6.7$ & $28.5 \pm 5.3$ & 1.000 \\
\hline Obesity & $5(41.7)$ & $2(33.3)$ & 0.732 \\
\hline Prior cervical fusion & $4(33.3)$ & $2(33.3)$ & 1.000 \\
\hline Current alcohol abuse & 0 & $1(16.7)$ & 0.146 \\
\hline Current smoker & 0 & $2(33.3)$ & $0.034 \dagger$ \\
\hline Illicit drug user & $1(8.3)$ & 0 & 0.467 \\
\hline CAD & $1(8.3)$ & $1(16.7)$ & 0.596 \\
\hline Osteoporosis & 0 & 0 & - \\
\hline COPD & $3(25.0)$ & $1(16.7)$ & 0.688 \\
\hline Current steroid use & 0 & 0 & \\
\hline Hyperlipidemia & $4(33.3)$ & $4(66.7)$ & 0.180 \\
\hline Hypertension & $9(75.0)$ & $6(100.0)$ & 0.180 \\
\hline \multicolumn{4}{|l|}{ Location/etiologies } \\
\hline Deformity & $4(33.3)$ & $1(16.7)$ & 0.457 \\
\hline Degenerative & $6(50.0)$ & $3(50.0)$ & 1.000 \\
\hline Neoplasm & $1(8.3)$ & $1(16.7)$ & 0.596 \\
\hline Trauma & $1(8.3)$ & $1(16.7)$ & 0.596 \\
\hline Cross CTJ & $6(50.0)$ & $4(66.7)$ & 0.502 \\
\hline \multicolumn{4}{|l|}{ Operative details } \\
\hline Mean no. of levels instrumented & $5.5 \pm 2.2$ & $6.7 \pm 2.4$ & 0.273 \\
\hline Mean EBL in $\mathrm{ml}$ & $368.8 \pm 382.2$ & $583.3 \pm 494.6$ & 0.420 \\
\hline Mean duration of anesthesia in mins & $339.2 \pm 132.2$ & $257.7 \pm 109.7$ & 0.426 \\
\hline Use of postop drain & $12(100.0)$ & $6(100.0)$ & - \\
\hline Intraop steroid use & $7(58.3)$ & $1(16.7)$ & 0.094 \\
\hline Blood transfusion & $2(16.7)$ & $3(50.0)$ & 0.137 \\
\hline Use of cell saver & 0 & 0 & - \\
\hline Dural tear & 0 & 0 & - \\
\hline \multicolumn{4}{|l|}{ Outcomes } \\
\hline Mean days to infection & $13.9 \pm 5.5$ & $22.3 \pm 7.0$ & $0.024 \dagger$ \\
\hline
\end{tabular}

in postoperative deep SSIs in posterior cervical spinal fusion cases $(n=289,6.9 \%$ vs $5.2 \%, p=0.563)$. This is in contrast to 2 prior, smaller cohort studies that reported significant reductions in the incidence of postoperative deep SSI in posterior cervical fusion cases. ${ }^{2,20}$ Likewise, the $1.7 \%$ reduction seen in our study is much smaller than the average $4.79 \%$ reduction seen in prior published studies. ${ }^{2,17,20}$ Spinal fusion patients are at a higher risk for infection due to very large incisional wounds, longer surgery time, duration of anesthesia, blood loss, ${ }^{26}$ and use of instrumentation. ${ }^{12} \mathrm{~A}$ possible theory for our results that are in contrast to those of other vancomycin studies is that local vancomycin may not have enough capacity to overcome the increased infection risk factors seen in patients undergoing fusion. Thus, the addition of other treatment modalities may be needed to prevent SSIs in the high-risk fusion population, such as improved nutrition or more stringent patient selection criteria. An additional consideration is that the current dosing of intrawound vancomycin may not be adequate, or the delivery of the medication does not last long enough in the local environment to completely control bacterial growth for these large, deep incisions. Interestingly, although culture results were not significantly different in either cohort, patients in the treated cohort had a higher mean number of postoperative days to infection (untreated 13.9 days, treated 22.3 days, $p=0.024$ ). A possible theory for this is that vancomycin may stave off immediate infections, but infections may manifest as the local levels of vancomycin decrease.

This study was larger than most of the prior cervical vancomycin powder studies, ${ }^{2,20}$ and it attempted to con- 
TABLE 3. Cervical fusion patients from treatment (vancomycin) group with deep postoperative SSI

\begin{tabular}{|c|c|c|c|c|c|c|c|c|c|}
\hline $\begin{array}{l}\text { Case } \\
\text { No. }\end{array}$ & $\begin{array}{l}\text { Age } \\
\text { (yrs), } \\
\text { Sex }\end{array}$ & Diagnosis & $\begin{array}{l}\text { Infection } \\
\text { Onset } \\
\text { (days) }\end{array}$ & Levels & $\begin{array}{l}\text { Tobacco } \\
\text { Use }\end{array}$ & DM & $\mathrm{BMI}$ & $\begin{array}{l}\text { Other Risk } \\
\text { Factors }\end{array}$ & Culture \\
\hline 1 & $51, F$ & $\begin{array}{l}\text { Cervical stenosis, pseud- } \\
\text { arthrosis }\end{array}$ & 23 & $\mathrm{C} 3-\mathrm{T} 2$ & Yes & Yes & 36 & Prior fusion & MSSA \\
\hline 2 & $74, \mathrm{M}$ & C5-6 fracture instability & 17 & C3-7 & No & Yes & 31.0 & Poor nutrition & $\begin{array}{l}\text { Enterobacter cloacae, Morgan- } \\
\text { ella morganii, Pseudomonas } \\
\text { aeruginosa }\end{array}$ \\
\hline 3 & $83, M$ & $\begin{array}{l}\text { Cervical stenosis, listhesis, } \\
\text { spondylosis }\end{array}$ & 27 & $\mathrm{C} 2-\mathrm{T} 2$ & No & No & 29.4 & CAD & $\begin{array}{l}\text { Coagulase-negative staphy- } \\
\text { lococci }\end{array}$ \\
\hline 4 & $56, M$ & $\begin{array}{l}\text { Hardware failure, cervical } \\
\text { stenosis, spondylosis }\end{array}$ & 29 & $\mathrm{C} 2-\mathrm{T} 2$ & No & No & 27.8 & $\begin{array}{l}\text { COPD, alcohol } \\
\text { abuse, prior } \\
\text { fusion }\end{array}$ & Diphtheroids \\
\hline 5 & $50, F$ & Cervical stenosis, kyphosis & 27 & $\mathrm{C} 2-\mathrm{T} 1$ & Yes & No & 26.7 & $\begin{array}{l}\text { ESRD, staged } \\
\text { procedure }\end{array}$ & $\begin{array}{l}\text { Coagulase-negative staphy- } \\
\text { lococci }\end{array}$ \\
\hline 6 & $61, M$ & Pathological fracture & 11 & C5-T5 & No & No & 20.1 & $\begin{array}{l}\text { Metastasis, poor } \\
\text { nutrition }\end{array}$ & Propionibacterium \\
\hline
\end{tabular}

$\mathrm{DM}=$ diabetes mellitus; $\mathrm{ESRD}$ = end-stage renal disease; MSSA = methicillin-sensitive Staphylococcus aureus.

TABLE 4. Cervical fusion patients from control (non-vancomycin) group with deep postoperative SSI

\begin{tabular}{|c|c|c|c|c|c|c|c|c|c|}
\hline $\begin{array}{l}\text { Case } \\
\text { No. }\end{array}$ & $\begin{array}{l}\text { Age } \\
\text { (yrs), } \\
\text { Sex }\end{array}$ & Diagnosis & $\begin{array}{c}\text { Infection } \\
\text { Onset } \\
\text { (days) }\end{array}$ & Levels & $\begin{array}{l}\text { Tobacco } \\
\text { Use }\end{array}$ & DM & $\mathrm{BMI}$ & $\begin{array}{l}\text { Other Risk } \\
\text { Factors }\end{array}$ & Culture \\
\hline 7 & $63, M$ & Cervical stenosis & 13 & C3-T1 & No & No & 43.6 & None & $\begin{array}{l}\text { Coagulase-negative } \\
\text { staphylococci }\end{array}$ \\
\hline 8 & $64, \mathrm{M}$ & $\begin{array}{l}\text { Severe cervical stenosis, } \\
\text { vascular insufficiency }\end{array}$ & 13 & C5-7 & No & Yes & 33.6 & Prior fusion & MSSA \\
\hline 9 & $55, F$ & Cervical stenosis, kyphosis & 22 & $\mathrm{C} 2-7$ & No & No & 24.2 & Cerebral palsy & Proteus mirabilis \\
\hline 10 & $69, \mathrm{~F}$ & Traumatic fracture & 17 & C3-T1 & No & No & 24.9 & $\begin{array}{l}\text { COPD, Hx radia- } \\
\text { tion }\end{array}$ & $\begin{array}{l}\text { Coagulase-negative } \\
\text { staphylococci }\end{array}$ \\
\hline 11 & $69, \mathrm{M}$ & Cervical stenosis & 7 & $\mathrm{C} 2-7$ & No & No & 25.8 & $\begin{array}{l}\text { COPD, prior } \\
\text { spinal fusion }\end{array}$ & MSSA \\
\hline 12 & $62, \mathrm{M}$ & Cervical stenosis & 14 & C3-T5 & No & No & 32.3 & Prior fusion & $\begin{array}{l}\text { Coagulase-negative } \\
\text { staphylococci, } \\
\text { Propionibacterium }\end{array}$ \\
\hline 13 & $83, F$ & $\begin{array}{l}\text { Occipitocervical instability, } \\
\text { cervical stenosis }\end{array}$ & 6 & Occiput-T2 & No & No & 22.2 & None & Serratia marcescens \\
\hline 14 & $57, \mathrm{M}$ & Cervical stenosis & 22 & C3-7 & No & Yes & 30.3 & None & $\begin{array}{l}\text { Coagulase-negative } \\
\text { staphylococci, } \\
\text { Escherichia coli }\end{array}$ \\
\hline 15 & $56, F$ & Cervical stenosis, kyphosis & 16 & $\mathrm{C} 2-\mathrm{T} 1$ & No & No & 21.3 & Staged procedure & $\begin{array}{l}\text { Coagulase-negative } \\
\text { staphylococci, } S \text {. } \\
\text { marcescens }\end{array}$ \\
\hline 16 & $47, \mathrm{~F}$ & Cervical stenosis, kyphosis & 9 & C3-7 & No & No & 37.0 & None & $\begin{array}{l}\text { Coagulase-negative } \\
\text { staphylococci }\end{array}$ \\
\hline 17 & $54, \mathrm{~F}$ & $\begin{array}{l}\text { Stenosis, adjacent-segment } \\
\text { disease }\end{array}$ & 19 & $\mathrm{C} 3-\mathrm{T} 1$ & No & Yes & 24.4 & $\begin{array}{l}\text { Prior fusion, CAD, } \\
\text { COPD }\end{array}$ & MSSA \\
\hline 18 & $66, M$ & $\begin{array}{l}\text { Prostate cancer metastasis, } \\
\text { T-2 cord compression }\end{array}$ & 9 & C7-T4 & No & No & 29.4 & Metastasis & $\begin{array}{l}\text { Peptostreptococcus, } \\
\text { Propionibacterium }\end{array}$ \\
\hline
\end{tabular}

$\mathrm{Hx}=$ history of. 
TABLE 5. Comparison of prior studies of local vancomycin powder for spinal fusion surgery

\begin{tabular}{|c|c|c|c|c|}
\hline Authors \& Year & Location & Etiology & $\begin{array}{l}\text { No. of Fusion } \\
\text { Cases }\end{array}$ & Infection Rate for Fusion Cases \\
\hline Sweet et al., 2011 & Thoracic, lumbar & All posterior fusion cases & 1732 & Control $2.6 \%$; treated $0.2 \%(p<0.001)$ \\
\hline O'Neill et al., 2011 & Cervical, thoracic, lumbar & Posterior trauma fusion cases & 110 & Control 13\%; treated $0 \%(p=0.02)$ \\
\hline Molinari et al., 2012 & Cervical, thoracic, lumbar & All spine cases & 663 & Treated $1.20 \%$ \\
\hline Strom et al., $2013^{21}$ & Lumbar & All posterior cases & 165 & Control $12 \%$; treated $0 \%(p<0.001)$ \\
\hline Strom et al., $2013^{20}$ & Cervical & All posterior fusion cases & 171 & Control $10.9 \%$; treated $2.5 \%(p=0.038)$ \\
\hline Caroom et al., 2013 & Cervical & $\begin{array}{l}\text { Posterior multilevel spondylotic } \\
\text { myelopathy fusion cases }\end{array}$ & 112 & Control $15 \%$; treated $0 \%(p=0.007)$ \\
\hline Gans et al., 2013 & Thoracic, lumbar & Pediatric deformity cases & 87 & Treated $3.4 \%$ \\
\hline Pahys et al., 2013 & Cervical & All posterior cases & 576 & $\begin{array}{l}\text { Control } 1.73 \% \text {; treated } 0 \% \text { (vancomycin + } \\
\text { alcohol foam + drain) }\end{array}$ \\
\hline Tubaki et al., 2013 & Cervical, thoracic, lumbar & All spine cases & 606 & Control $1.98 \%$; treated $1.99 \%$ \\
\hline
\end{tabular}

trol for many spinal SSI risk factors including diabetes, long-term steroid use, previous spinal surgery, obesity, smoking, duration of anesthesia, EBL, drug use, ${ }^{26}$ blood transfusion, coronary artery disease, osteoporosis, dural tear, and COPD. ${ }^{8}$ Vancomycin-treated patients were slightly older. This factor could potentially increase the risk of deep infection in the treatment group. However, our logistic regression analysis controlling for risk factors and operative details did not show an impact for vancomycin in affecting incidence of infection.

Our study has several limitations that are subject to interpretation. With the sample and small infection rates observed, this study is underpowered for vancomycin to predict SSI. Sample sizes of more than 3000 patients in each cohort would be required to adequately power this study, given the infection rates that were found in each cohort. However, our sample size $(n=289)$ was large enough to detect the effect of vancomycin on infection rates in both prior posterior cervical fusion vancomycin studies. ${ }^{2,20}$ This study was limited by its retrospective design, focus on fusion cases, and resulting confounding factors that may have been undetected. We also focused on deep wound complications within the 30-day postoperative period, not accounting for superficial or possible late infections. The study involved 8 surgeons who have fairly similar techniques. However, there could have been subtle surgical variations. Both cohorts centered on the introduction of vancomycin powder, which initially began due to surgeon's discretion and may have introduced selection bias. Likewise, procedure bias may have been introduced by the surgeon in the treated cohort, such as quantity of wound irrigation or other types of infection control techniques. However, note that the distribution of infections showed that no one surgeon had a significantly greater infection rate, and no surgeon had a change in infection rate before and after the introduction of vancomycin. Furthermore, there was no difference in wound surveillance techniques or infection event recognition in either cohort. Additionally, serum vancomycin levels were not measured, which could have aided in proper dosing and assessing its duration of impact. Finally, drains were common in this series and could have drained or limited the vancomycin concentration. ${ }^{22}$ Despite these limitations, our study demonstrated that the use of locally ap- plied vancomycin powder did not significantly reduce the incidence of 30-day postoperative deep SSI rate in open posterior cervical fusion.

\section{Conclusions}

This retrospective cohort study compared postoperative deep SSI rates in a continuous cohort of patients undergoing posterior cervical fusion surgery before and after the routine application of locally applied vancomycin powder. No significant change in deep wound infection rate was seen between the control group (6.9\%) and intervention group $(5.2 \%, \mathrm{p}=0.563)$. This study is in contrast to prior cervical spinal studies, which have reported a statistically significant and larger decrease in SSI with the addition of perioperative intrawound vancomycin powder. ${ }^{2,17,20}$ Future randomized prospective studies are needed to corroborate our findings.

\section{References}

1. Anderson DJ, Kaye KS, Classen D, Arias KM, Podgorny K, Burstin H, et al: Strategies to prevent surgical site infections in acute care hospitals. Infect Control Hosp Epidemiol 29 (Suppl 1):S51-S61, 2008

2. Caroom C, Tullar JM, Benton EG Jr, Jones JR, Chaput CD: Intrawound vancomycin powder reduces surgical site infections in posterior cervical fusion. Spine (Phila Pa 1976) 38:1183-1187, 2013

3. Gans I, Dormans JP, Spiegel DA, Flynn JM, Sankar WN, Campbell RM, et al: Adjunctive vancomycin powder in pediatric spine surgery is safe. Spine (Phila Pa 1976) 38:17031707, 2013

4. Godil SS, Parker SL, O'Neill KR, Devin CJ, McGirt MJ: Comparative effectiveness and cost-benefit analysis of local application of vancomycin powder in posterior spinal fusion for spine trauma. Clinical article. J Neurosurg Spine 19:331-335, 2013

5. Gruskay J, Kepler C, Smith J, Radcliff K, Vaccaro A: Is surgical case order associated with increased infection rate after spine surgery? Spine (Phila Pa 1976) 37:1170-1174, 2012

6. Kirkland KB, Briggs JP, Trivette SL, Wilkinson WE, Sexton DJ: The impact of surgical-site infections in the 1990s: attributable mortality, excess length of hospitalization, and extra costs. Infect Control Hosp Epidemiol 20:725-730, 1999

7. Klevens RM, Edwards JR, Richards CL Jr, Horan TC, Gaynes RP, Pollock DA, et al: Estimating health care-asso- 
ciated infections and deaths in U.S. hospitals, 2002. Public Health Rep 122:160-166, 2007

8. Koutsoumbelis S, Hughes AP, Girardi FP, Cammisa FP Jr, Finerty EA, Nguyen JT, et al: Risk factors for postoperative infection following posterior lumbar instrumented arthrodesis. J Bone Joint Surg Am 93:1627-1633, 2011

9. Lazar HL, Barlam T, Cabral H: The effect of topical vancomycin applied to sternotomy incisions on postoperative serum vancomycin levels. J Card Surg 26:461-465, 2011

10. Mangram AJ, Horan TC, Pearson ML, Silver LC, Jarvis WR: Guideline for prevention of surgical site infection, 1999. Infect Control Hosp Epidemiol 20:250-278, 1999

11. Mariappan R, Manninen P, Massicotte EM, Bhatia A: Circulatory collapse after topical application of vancomycin powder during spine surgery. Case report. J Neurosurg Spine 19:381-383, 2013

12. Massie JB, Heller JG, Abitbol JJ, McPherson D, Garfin SR: Postoperative posterior spinal wound infections. Clin Orthop Relat Res (284):99-108, 1992

13. Mohammed S, Pisimisis GT, Daram SP, Bechara CF, Barshes NR, Lin PH, et al: Impact of intraoperative administration of local vancomycin on inguinal wound complications. J Vasc Surg 57:1079-1083, 2013

14. Molinari RW, Khera OA, Molinari WJ III: Prophylactic intraoperative powdered vancomycin and postoperative deep spinal wound infection: 1,512 consecutive surgical cases over a 6-year period. Eur Spine J 21 (Suppl 4):S476-S482, 2012

15. O'Neill KR, Smith JG, Abtahi AM, Archer KR, Spengler DM, McGirt MJ, et al: Reduced surgical site infections in patients undergoing posterior spinal stabilization of traumatic injuries using vancomycin powder. Spine J 11:641-646, 2011

16. Ozcan AV, Demir M, Onem G, Goksin I, Baltalarli A, Topkara VK, et al: Topical versus systemic vancomycin for deep sternal wound infection caused by methicillin-resistant Staphylococcus aureus in a rodent experimental model. Tex Heart Inst J 33:107-110, 2006

17. Pahys JM, Pahys JR, Cho SK, Kang MM, Zebala LP, Hawasli $\mathrm{AH}$, et al: Methods to decrease postoperative infections following posterior cervical spine surgery. J Bone Joint Surg Am 95:549-554, 2013

18. Pull ter Gunne AF, Cohen DB: Incidence, prevalence, and analysis of risk factors for surgical site infection following adult spinal surgery. Spine (Phila Pa 1976) 34:1422-1428, 2009

19. Smith JS, Shaffrey CI, Sansur CA, Berven SH, Fu KM, Broadstone PA, et al: Rates of infection after spine surgery based on 108,419 procedures: a report from the Scoliosis Research Society Morbidity and Mortality Committee. Spine (Phila Pa 1976) 36:556-563, 2011
20. Strom RG, Pacione D, Kalhorn SP, Frempong-Boadu AK: Decreased risk of wound infection after posterior cervical fusion with routine local application of vancomycin powder. Spine (Phila Pa 1976) [epub ahead of print], 2013

21. Strom RG, Pacione D, Kalhorn SP, Frempong-Boadu AK: Lumbar laminectomy and fusion with routine local application of vancomycin powder: decreased infection rate in instrumented and non-instrumented cases. Clin Neurol Neurosurg 115:1766-1769, 2013

22. Sweet FA, Roh M, Sliva C: Intrawound application of vancomycin for prophylaxis in instrumented thoracolumbar fusions: efficacy, drug levels, and patient outcomes. Spine (Phila Pa 1976) 36:2084-2088, 2011

23. Tubaki VR, Rajasekaran S, Shetty AP: Effects of using intravenous antibiotic only versus local intrawound vancomycin antibiotic powder application in addition to intravenous antibiotics on postoperative infection in spine surgery in 907 patients. Spine (Phila Pa 1976) 38:2149-2155, 2013

24. Vander Salm TJ, Okike ON, Pasque MK, Pezzella AT, Lew $\mathrm{R}$, Traina V, et al: Reduction of sternal infection by application of topical vancomycin. J Thorac Cardiovasc Surg 98:618-622, 1989

25. Whitehouse JD, Friedman ND, Kirkland KB, Richardson WJ, Sexton DJ: The impact of surgical-site infections following orthopedic surgery at a community hospital and a university hospital: adverse quality of life, excess length of stay, and extra cost. Infect Control Hosp Epidemiol 23:183-189, 2002

26. Wimmer C, Gluch H, Franzreb M, Ogon M: Predisposing factors for infection in spine surgery: a survey of 850 spinal procedures. J Spinal Disord 11:124-128, 1998

27. Zeidman SM, Ducker TB, Raycroft J: Trends and complications in cervical spine surgery: 1989-1993. J Spinal Disord 10:523-526, 1997

\section{Author Contributions}

Conception and design: Gottfried. Acquisition of data: Martin. Analysis and interpretation of data: Gottfried, Martin. Drafting the article: Martin. Critically revising the article: all authors. Reviewed submitted version of manuscript: all authors. Approved the final version of the manuscript on behalf of all authors: Gottfried. Statistical analysis: Kuchibhatla. Study supervision: Gottfried.

\section{Correspondence}

Oren N. Gottfried, Duke University Medical Center, Box 3807, Durham, NC 27701. email: oren.gottfried@dm.duke.edu. 